\title{
Research Paper \\ Investigating the Mediating Role of Meaning of Education in the Relationship between Academic Optimism and Academic Performance of Students
}

\author{
Laya Jafari ${ }^{1}$, Masoud Hejazi ${ }^{* 2}$, Akbar Jalili ${ }^{2}$, Afsaneh Sobhi ${ }^{2}$ \\ 1. Ph.D. Student of Educational Psychology, Zanjan Branch, Islamic Azad University, Zanjan, Iran \\ 2. Assistant Professor, Department of Psychology, Zanjan Branch, Islamic Azad University, Zanjan, Iran
}

Citation: Jafari L, Hejazi M, Jalili A, Sobhi A. Investigating the mediating role of meaning of education in the relationship between academic optimism and academic performance of students. J Child Ment Health. 2021; 8 (1):14-26.

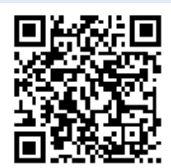

URL: http://childmentalhealth.ir/article-1-1083-en.html

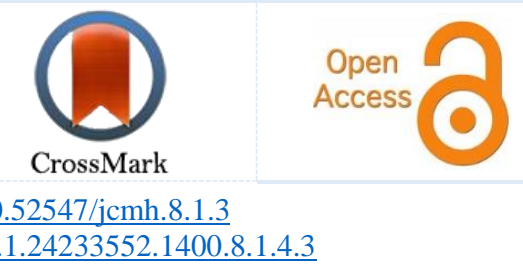

\section{A R T I C L E I N F O}

\section{Keywords:}

Academic optimism, academic performance, meaning of education, students

Received: 5 Dec 2020 Accepted: 2 May 2021 Available: 8 Jun 2021

\section{A B S T R A C T}

Background and Purpose: Academic performance is one of the important components in education that has always been addressed by programmers, school principals, teachers, and parents, who have always tried to provide appropriate conditions for enhancing the academic efficiency of students. This study was conducted to investigate the mediating role of meaning of education in the relationship between academic optimism and academic performance.

Method: This study was an applied research in terms of research objective and a descriptivecorrelational study in terms of gathering the data. Data were collected from a sample of 250 secondary school girls in Khorramdareh by random cluster sampling. Meaning of education Questionnaire (Henderson-King\& Smith, 2006) and Academic Optimism Scale (Tschanen-Moran et al., 2013) were used to collect the data. Also to evaluate the academic achievement, the average score of students in the first and second semesters were used. Data were analyzed by structural equations in SPSS22 and MPLUS 7.4.

Results: Findings showed that there was a significant positive relationship between academic optimism and academic performance $(\mathrm{P}<0.01)$ and that meaning of education plays a mediating role in this relationship.

Conclusion: The results show that academic optimism directly improves students 'academic performance, but it affects indirectly the academic performance through the mediating role of meaning of education.

* Corresponding author: Masoud Hejazi, Assistant Professor, Department of Psychology, Zanjan Branch, Islamic Azad University, Zanjan, Iran. E-mail: Masoud1357@yahoo.com

Tel: (+98) 2433421001

2476-5740/ (C) 2021 The Authors. This is an open access article under the CC BY-NC-ND license

(https://creativecommons.org/licenses/by-nc-nd/4.0/). 


\section{Extended Abstract}

\section{Introduction}

Academic performance is a significant educational element which has always been addressed by programmers, school principals, teachers, and parents (1), who have frequently tried to increase the efficiency of students. Academic performance includes all activities and efforts made by a person to acquire knowledge and pass the academic courses in the school, determined by the success in passing the final exams (2).

Academic optimism is among the cognitive factors related to academic performance (5). It defines the students' positive attitude to improve their academic performance by focusing on learning, relying on teachers, and feeling belonging to the academic environment (6). Academic optimism plays an important role in the learning and success; and it can be acquired regardless of student's ability and motivation (7).

Meaning of education is another factor influencing the student's involvement in the academic process. Some researches have addressed this issue that what does the education mean to the students (15). Meaning of education has several components, including profession, autonomy, future, self-growth, next step, social dimension, surrounding world, mental tension, and release (16).

The level of optimism has a high influence on the personal attitude and it can act as an efficient predictor of behavior. Also, optimism is directly associated with this belief that study can result in better learning, self-development, social relations, and change of the world, because these concepts include more positive attitude toward future (22). Alongside, considering the importance of academic optimism and meaning of education in predicting the academic performance and considering this fact that no research has yet investigated the relationship between these variables in an integrated model, this study aimed to explore the relationship between them through the mediating role of meaning of education.

\section{Method}

This study was an applied research in its aim and a descriptive-correlational study in the method of gathering the data. Structural equation modeling was used to investigate the relationship between the variables. The study population included all the girls studying at the second cycle of secondary school in Khoramdareh in the academic year 2019-2020. The sample consisted of 250 students selected by random cluster sampling. Inclusion criteria were studying at grades 10 to 12 and being a female; while the exclusion criterion was unwillingness to answer the questionnaires. It is worth mentioning that to assess the academic achievement, the average score at the first and second semesters were used. Data were gathered by Henderson-King \& Smith's Meaning of Education Questionnaire (27) and Tschanen-Moran et al.'s Academic Optimism Scale (28). After implementing the questionnaires on the sample, the statistical assumptions were tested by structural equation modeling in Mplus 7.4 and SPSS.

\section{Results}

Results of Pearson correlation matrix showed that there was a significant positive relationship between these variables: meaning of education and academic optimism ( $r=0.516, p<0.001)$, meaning of education and academic performance $(\mathrm{r}=0.0632, \mathrm{p}<0.001)$, and academic optimism and academic performance $(\mathrm{p}<0.001, \mathrm{r}=0.0649)$.

To examine the assumptions by structural equation modeling, Mplus 7.4 was used. First, indicators of model fitness were investigated; all of which approved fitness of the proposed model (RMSEA $=0.078, \mathrm{TLI}=0.920, \mathrm{CFI}=0.937$, SRMS $=0.045$ ). The determination coefficient of academic performance indicating that independent and mediator variables, i.e. academic optimism and meaning of education, predicted $62 \%$ of academic performance, which is a high amount. Also, the determination coefficient for meaning of education was $30 \%$ which is at intermediate level. Direct relationships between the variables in the final model showed that all path coefficients in the sample were statistically significant. To explore the significance of the mediating relationship and the indirect effect of the independent variable on the dependent variable 
through the mediator, Bootstrap method of Preacher \& Hayes was used, implying that meaning of education plays a mediating role in the relationship between academic optimism and academic performance in the secondary school girls of Khoramdareh.

\section{Conclusion}

To investigate the relationship between academic optimism and academic performance in students and to explore the mediating role of the meaning of education in this relationship, a model was designed. The academic optimism as the extraneous variable in this model affects the academic performance, directly or indirectly. This finding coincides several researches $(11,12,13,14)$. Optimism is known as having positive attitude towards the world, performance, and the outcomes. Hence, it can positively impact the formation of meaning in one's mind. Optimism reflects an orientation in which usually positive outcomes are expected and these outcomes are considered as the result of fixed, general, and internal factors.

This study also indicates that meaning of education is associated with academic performance and this result is in consistency with different studies $(4,19$, 20, 21, 27). To explain these findings, it can be said that cognitive and emotional factors involving education are very effective on the scientific enhancement and achievement of students and enhancement of emotional dimensions involved in education can positively affect the cognitive dimensions of students. Therefore, besides the educational affairs, attention should be paid to the feelings and emotions of students. Another finding shows that there is a positive significant relationship between academic optimism and meaning of education. This is in consistency with $23 \& 24$, but does not correspond to 25 . This inconsistency may be due to the difference in methodologies. In general, it can be said that increase of academic optimism in students can strengthen different dimensions of meaning of education. These variables together can improve the academic performance of students. Results obtained through data collection and model implementation indicated that the relationship assumptions in the model were positive and significant. Results showed that meaning of education acts as a mediator between academic optimism and academic performance, in such a way that increase of academic optimism in students can reinforce meaning of education in different aspects; thus put together they can improve the academic performance of students.

Finally, results of this research should be considered in the context of its limitations. Among the limitations, gender and self-report questionnaires can be mentioned. Also, the parental level of education and the economic status of the family were not controlled, although they may influence the educational methods of parents. By removing the limitations, next studies can increase the authenticity and generalization of results.

\section{Ethical Considerations}

Compliance with ethical guidelines: This study was conducted as per Permission No. 1234 dated 22 Dec. 2020 issued by Education Administration of Khoramdareh. Full informed consent of the participants, confidentiality and privacy were observed.

Funding: The present study was carried out as a Ph.D. thesis, with no financial support.

Authors' contribution: This study was extracted from the Ph.D. thesis of Laya Jafari in the field of Educational Psychology at Zanjan Branch of Islamic Azad University, bearing Code 13820702972014 dated 05 Nov. 2020. The first author was the senior researcher, the second author was the supervisor, and the third and fourth ones were the advisors.

Conflict of interest: This study was conducted with no conflict of interest and the results have been reported vividly.

Acknowledgments: The authorities of Education Administration of Khoramdareh, especially the expert of security who coordinated with the schools, the executive staff, the teachers, and the students are sincerely appreciated. 


\section{تعيين نقش ميانجى معناى تحصيلى در رابطه بين خوشبينى تحصيلى با عملكرد تحصيلى دانش آموزان

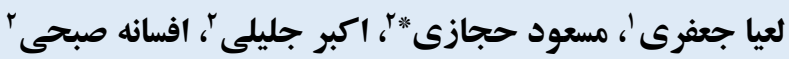

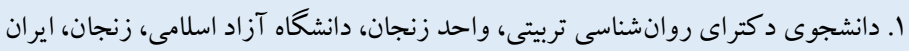

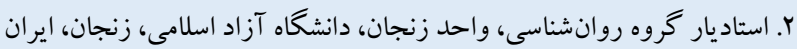

\section{جكيله}

زمينه و هدف: عملكرد تحصيلى يكى از مؤلفهاى مهم در آموزشويرورش است كه همواره مورد توجه برنامهريزان، مديران، معلمان، و والدين دانش آموزان بوده است و اين افراد همواره در تلاش هستند تا شرايطى را فراهم كنند كه كار آيى تحصيلى دانش آموزان بـان بالا برود. مقاله حاضر با هدف بررسى نقش ميانجى معناى تحصيلى در رابطه بين خوشينى تحصيلى با عملكرد تحصيلى دانش آموزان انجام شد.

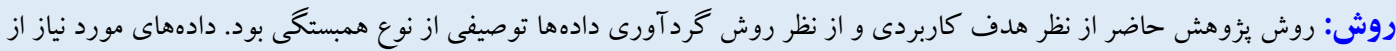

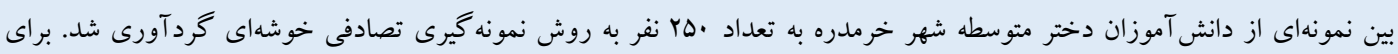

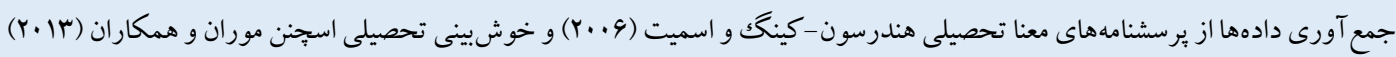
استفاده شده است. همجنين براى سنجش موفقيت تحصيلى از معدل كسب شده توسط دانش آموزان در دو نيمسال اول و دوم استفاده شد.

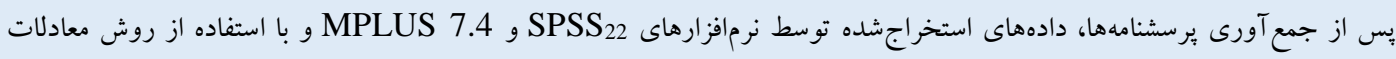
ساختارى بررسى و تحليل شد.

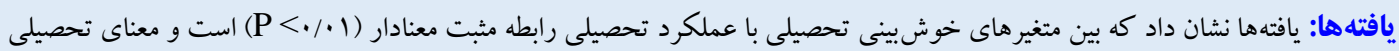
بين دو متغير خوش بينى تحصيلى و عملكرد تحصيلى نقش ميانجى بازى مى كند. نتيجه كيرى: نتايج نشان مىدهد كه خوشيني دينى تحصيلى به صورت مستقيم موجب بهبود عملكرد تحصيلى دانش آموزان مىشود، اما به

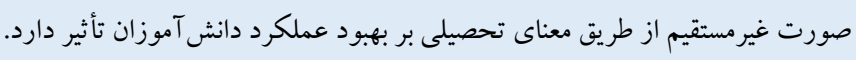

مشخصات مقاله

كليدوازهها:

خوشينى تحصيلى،

عملكرد تحصيلى،

معناى تحصيلى،

دانش آموزان

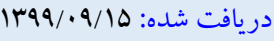

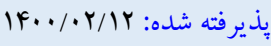

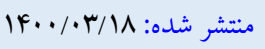

* نويسنده مسئول: مسعود حجازى، استاديار گروه روانشناسى، واحد زنجان، دانشكاه آزاد اسلامى، زنجان، ايران.

Masod1357@yahoo.com

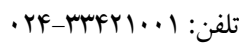


(11). در بزوهشسى ديخر گزارش كردند كه بين خوشبينى تحصـيلى و

موفقيـت تحصـيلى دانش آموزان رابطه مثبـت معنادار وجود دارد (Y ( ).

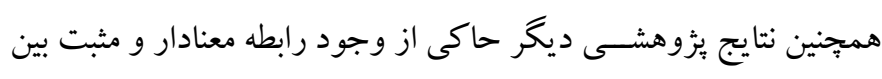

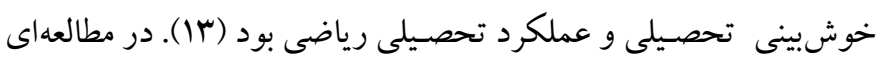

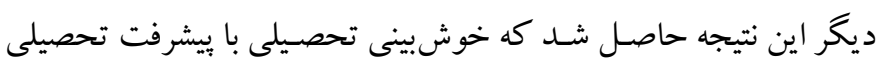

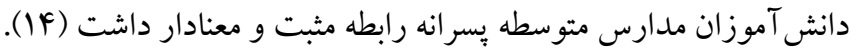

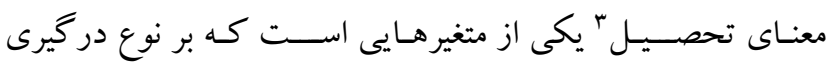

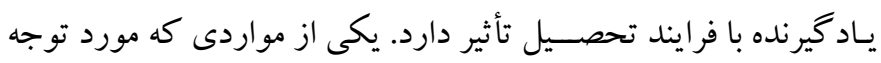

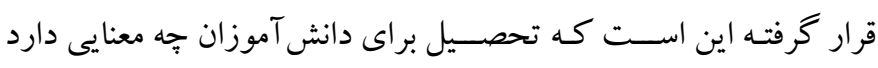

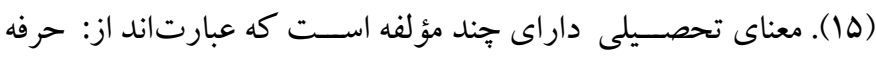

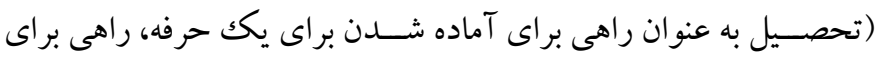

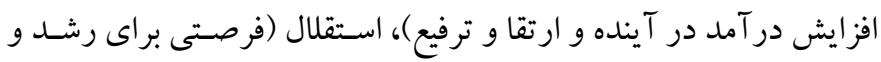

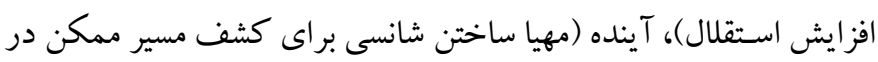

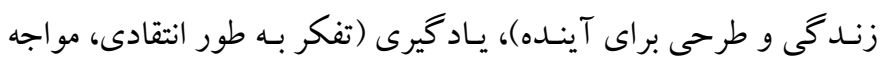

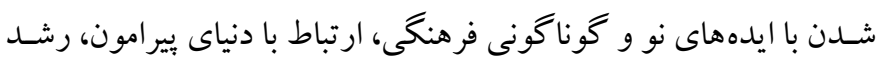

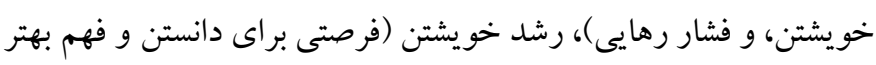

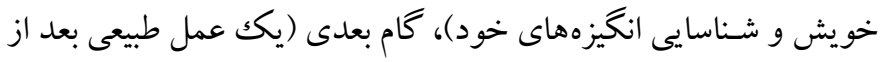

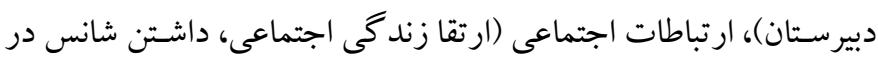
كسترش دوستىها، مشار كت در برخى فعاليتهاى فوق برنامه)، تغيير دنيا

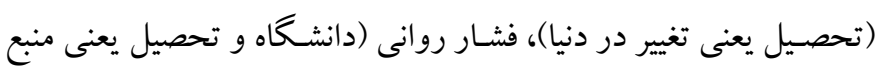

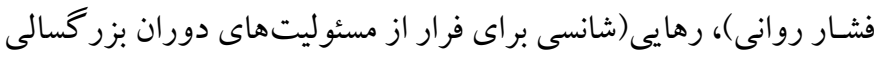

يا فرار از يكك موقعيت زندكى برتنش) (19).

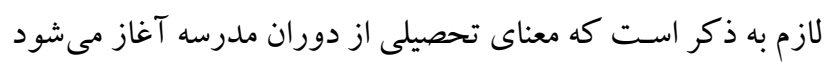

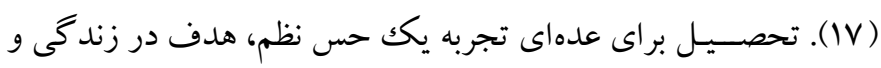

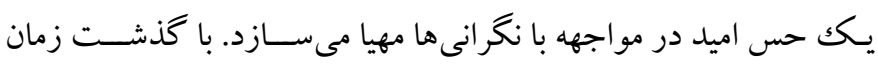

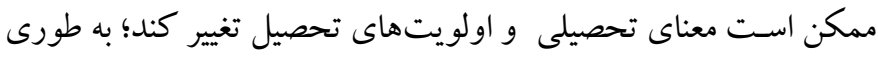

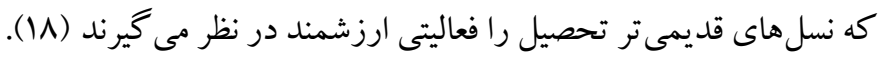

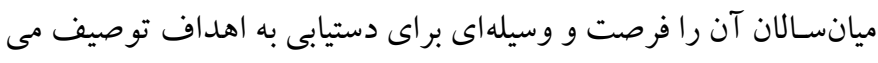

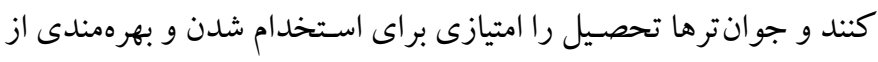

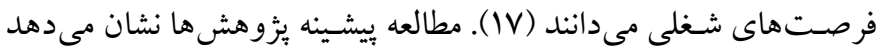

مقدمه

دانش آموزان از سرمايههاى انسانى هر جامعهاى به شمار مىروند و سالانه

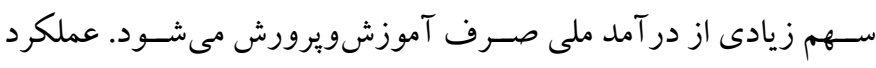

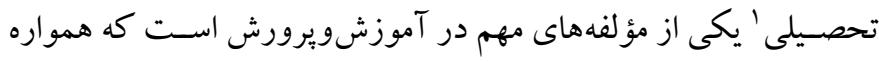

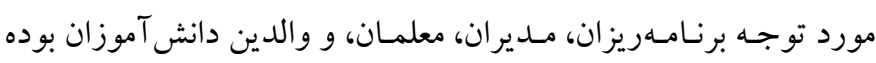

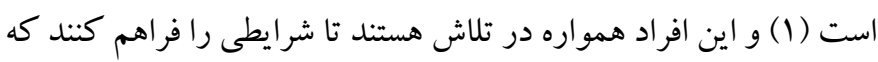

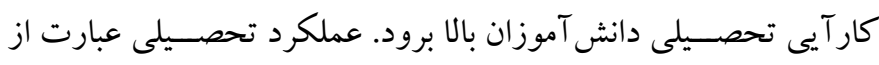

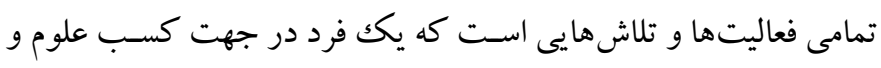
دانش و كذراندن يايهها و مقاطع تحصيلى مختلف در مراكز آموزشى از

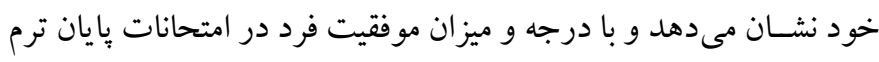
تحصسيلى مدارس كه از نمره صـفر تا بيسـت اسـت، تعيين مى شــود (Y). عملكرد تحصيلى به دلالت درونى تحصيل براى دانش آموز اشاره دارد و

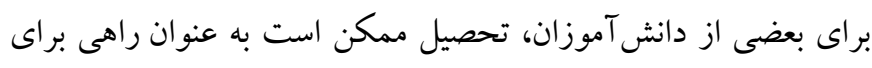

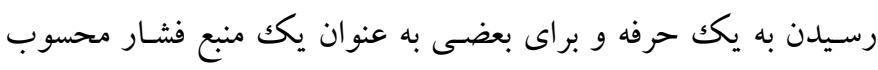

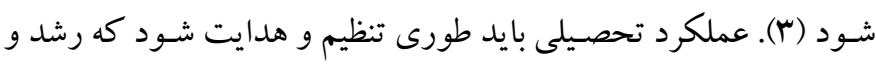

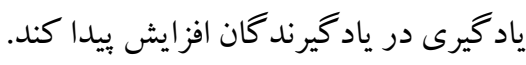

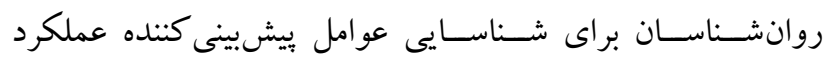
تحصسيلى تاكنون متغيرهاى زيادى را مورد بررسسى قرار دادهاند (F).

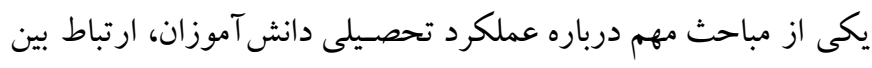

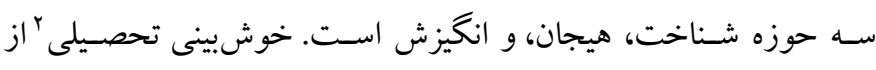
عوامل شناختى مرتبط با عملكرد تحصيلى است (ه). خوش بينى تحصيلى

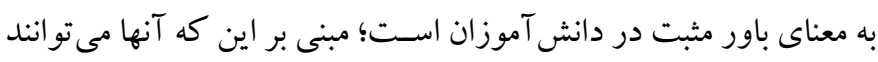

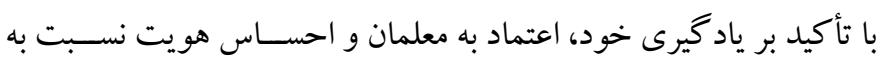

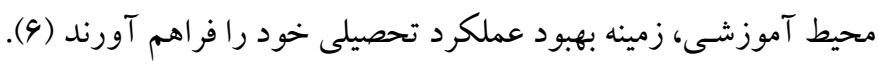
خوش بينى تحصـيلى نقش مهمى در موفقيـت و يـاد كيرى دانش آموزان

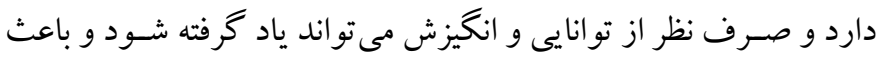
بهبود محيط تحصسيلى شـود (V). نتايج يزوهش ها حاكى از رابطه معنادار

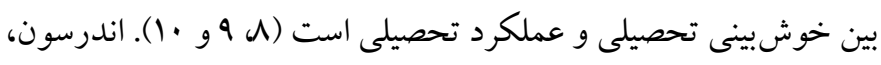

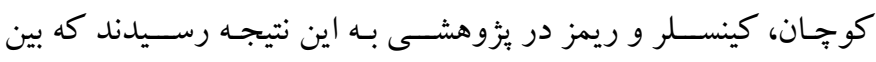

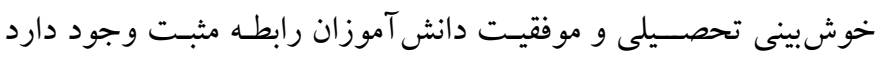




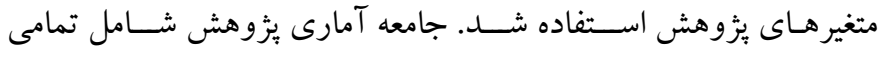

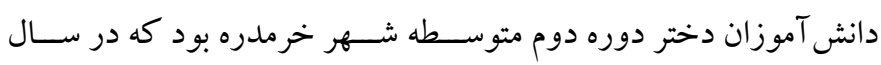

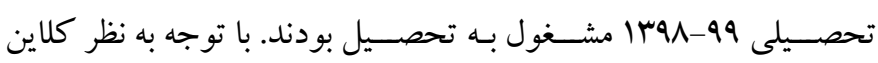

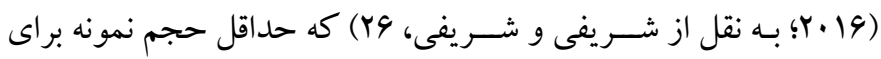

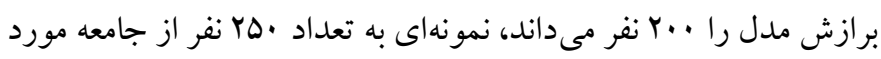

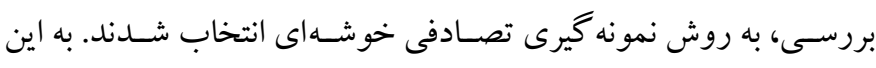

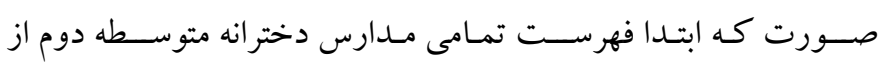

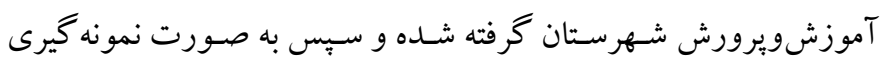

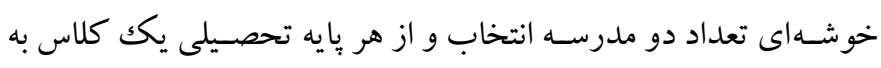

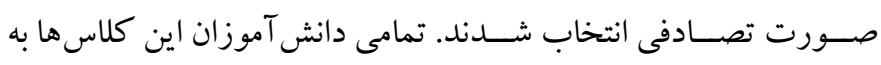

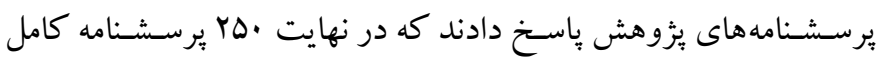

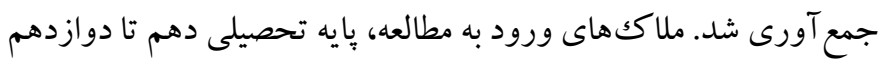

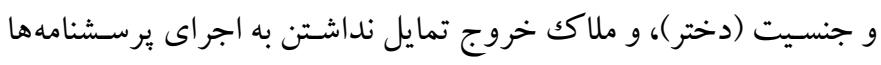

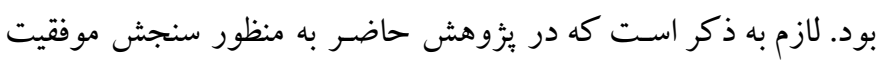
تحصيلى از ميزان معدل كسـب شده توسط دانش آموزان در دو نيمسال

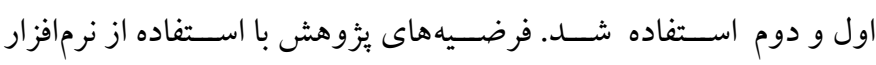

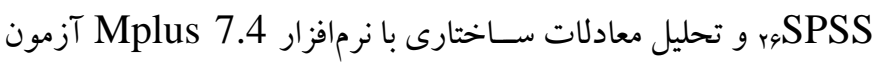

شد.

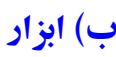

ا ـ مقياس معناى تحصسيلى': اين يرسشنامه را هندرسون-كينگك و اسميت (YV)

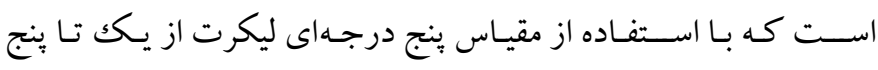

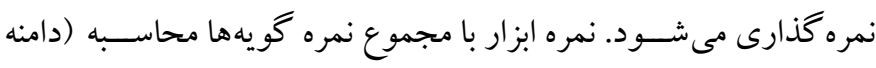

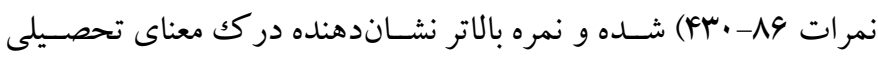

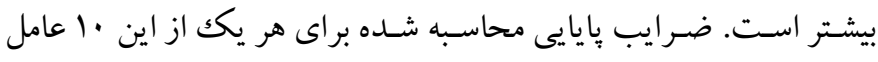

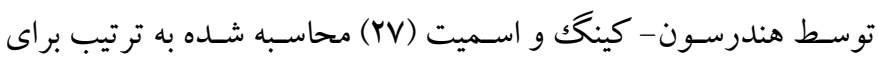

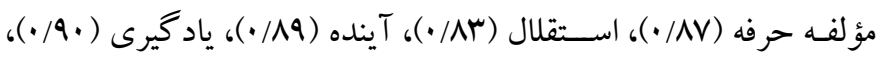

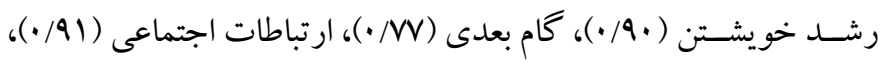

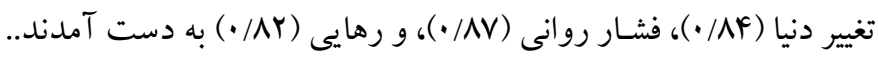

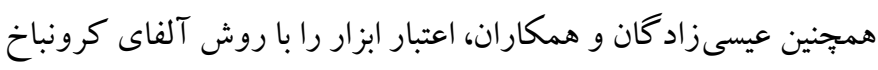

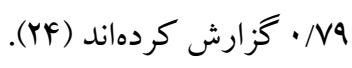

كه رابطه مثبت بين متغير معناى تحصيلى با عملكرد تحصيلى تأييد شده

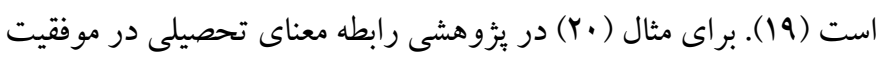

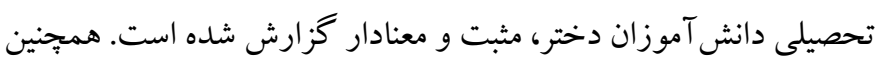
در بزوهشى مشابه رابطه بين معناى تحصيلى و عملكرد تحصيلى مثبت و

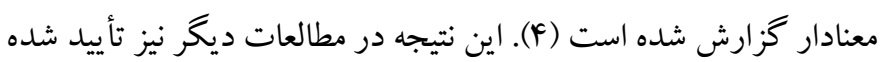

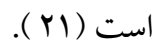

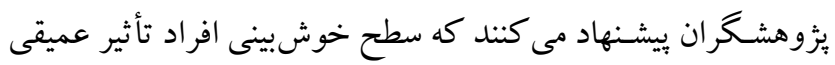

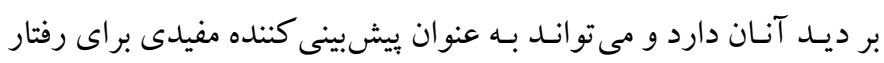

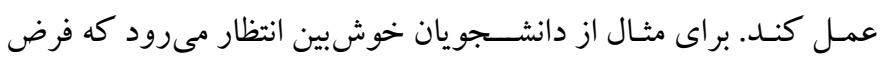

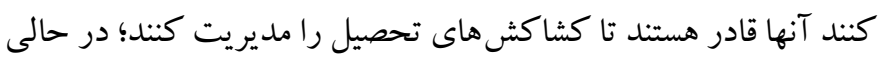
كه دانشــجويان بدبين، كمتر جنين كارى مى كنند. علاوه بر اين معتقديم

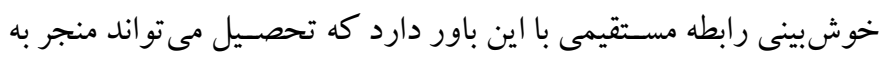

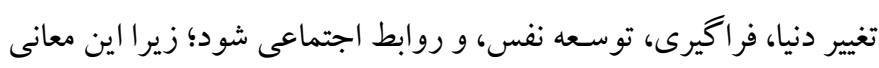

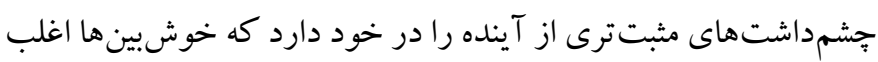

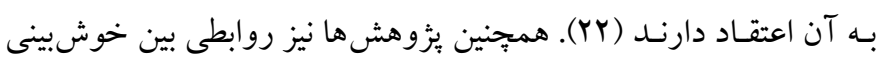

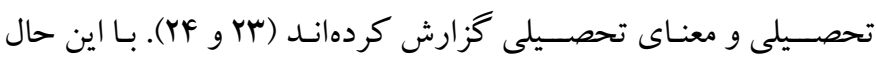
يُزوهش هاى متناقضسى نيز وجود دارد كه معتقدند بين معناى تحصسيلى و خوش بينى رابطه معنادارى وجود ندارد. به عنوان مثال در مطالعهاى (YD) رابطه معنادارى بين معناى تحصيلى و خوش بينى تحصيلى زز ارش نش نشده

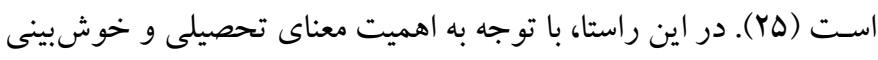

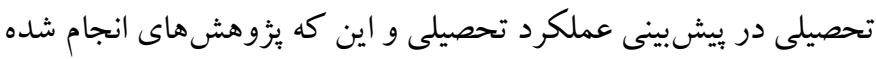

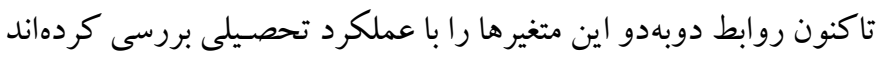

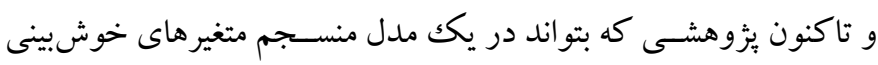

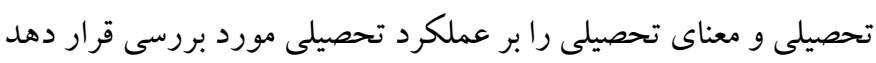

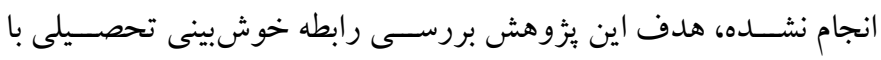
عملكرد تحصيلى با ميانجى گرى معناى تحصيلى است.

روش الف) طرح بزؤوه و شـر كت كنند كان: روش يزوهش حاضـر از نظر

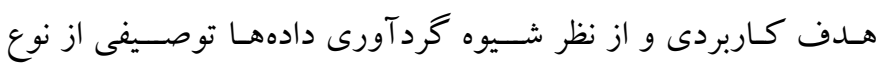

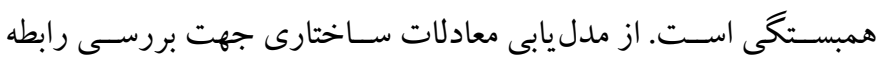


ج) روش اجرا: با اخذ مجوزهاى لازم از سازمان آموزشويرورش استان،

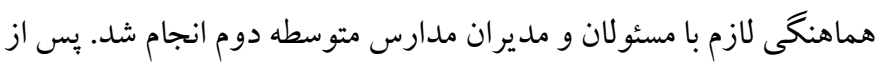

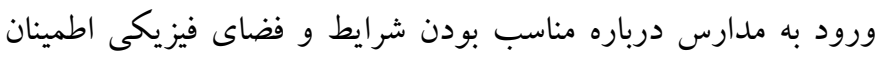

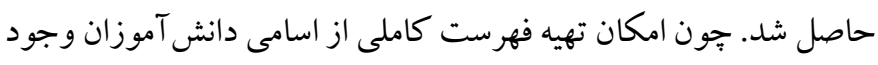
نداشت، در جنين شرايطى از روش نمونه گيرى خوشهاى كه به طور كامل در بخش طرح يزوهش توضيح داده شد، استفاده شد. در نهايت از طريق مشورت با مديران مدارس، ضمن رعايت ملاحظات اخلاقى و توضيحات

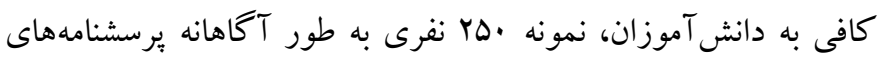

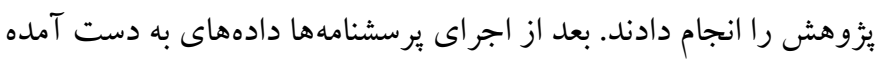

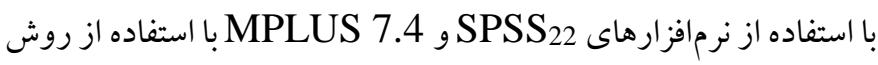
معادلات ساختارى بررسى و تحليل شدند.

يافته ها محاسبه ميانگين و انحر اف معيار متغيرها و مؤلفههاى بزوهش محاسبه شد.

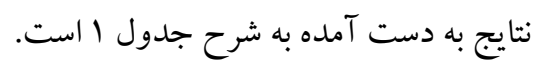

r.r.مقياس خوشبينى تحصــلى": منظور از خوشيينى تحصـيلى نمرات

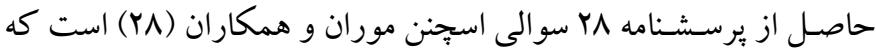

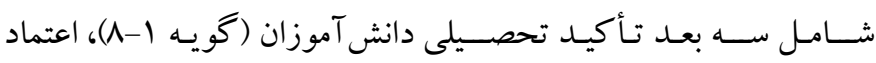

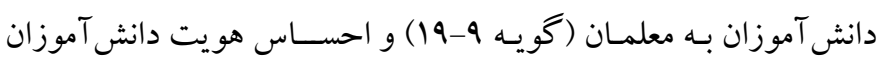

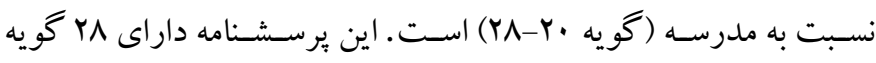
است كه بر اساس مقياس ليكرت از خيلى كم (1) تا خيلى زياد (ه) تنظيم

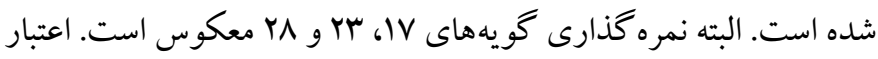

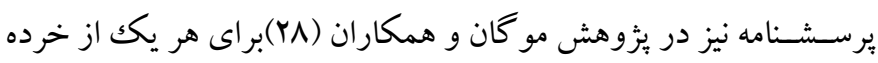

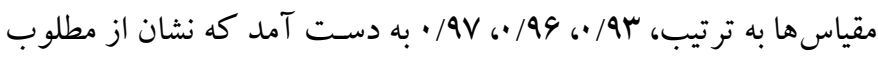

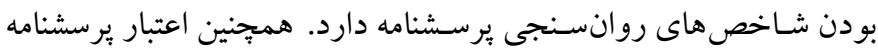
در يزوهش مر ادى و همكاران براى هر يـك از خردهمقيـاس ها به ترتيب

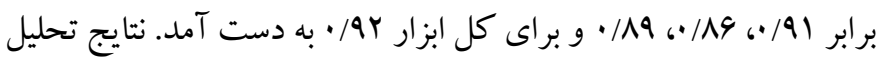

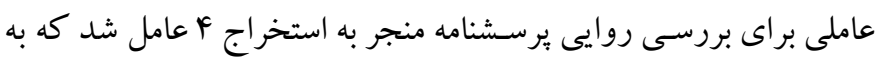
طور كلى (1 درصد از واريانس كل برسشنامه را تبيين مى كرد (Y) (Y).

جدول ا: شاخصهاى توصيفى (ميانكين و انحر اف معيار) متغيرهاى ئوهش (تعداد: •ro)

\begin{tabular}{|c|c|c|c|c|c|}
\hline كشيدكى & كجى & بيشينه -كمينه & انحراف معيار & ميانكين & متغير \\
\hline$\cdot / / r v$ & $-\cdot / \Delta \Delta r$ & $k r \cdot-19$ & $v q / 4$. & $r .9 / r 1$ & معناى تحصيلى \\
\hline-.1999 & $-\cdot / A A V$ & $\Delta \Delta-11$ & $\mid r / N r$ & rV/FA & حرفه \\
\hline-.1 .99 & $-\cdot / M A 9$ & $r \Delta-\Delta$ & $9 / .1$ & IN/V9 & استقلال \\
\hline$-\cdot / 1 \cdot 9$ & $-\cdot / \Delta V F$ & $10-r$ & $r / Y F$ & $1 \cdot / \mathrm{AV}$ & آينده \\
\hline$-\cdot / r \cdot 1$ & $-\cdot N F 9$ & $\Delta \cdot-1$. & $11 / 91$ & re/94 & ياد يرى \\
\hline$-\cdot /$ rar &.$- / v 9 \Delta$ & $\Delta \Delta-11$ & $1 \% / 94$ & $r \cdot N$. & رشد خويشتن \\
\hline$-\cdot / r \mid V$ &.$- / 1099$ & $10-r$ & $r / T r$ & $1 \cdot / \mathrm{VV}$ & كام بعدى \\
\hline$-\cdot / 10$ & $-. / 9 \mathrm{~V} \mid$ & $4 \cdot-14$ & $1 F / .1$ & $\kappa \kappa / .1$ & ارتباطات اجتماعى \\
\hline$-\cdot / 9 \wedge F$ & $-\cdot / 4 \cdot 1$ & r.-^ & $9 / 99$ & YN/.9 & تغيير دنيا \\
\hline.$- / 9 M$ &.$- / 494$ & 4.-Ir & $|F / 1|$ & FI/vG & فشار روانى \\
\hline$-\cdot / v \Delta v$ & $-\cdot /$ TYA & $\Delta \Delta-11$ & $\mid r / T V$ & $r v / I r$ & رهايى \\
\hline$-\cdot / \& \Delta V$ & - & $\mid F \cdot-r \Lambda$ & TAN. & 9V/94 & خوشينى تحصيلى \\
\hline-.1911 & $-\cdot /$ YAD & $f \cdot-\Lambda$ & A/va & TV/NI & تأكيد تحصيلى \\
\hline$-\cdot / \Delta 94$ &.$- / \mu F$ & $0 \cdot-1$. & $11 / / V$ & $r \Delta / \cdot \varphi$ & اعتماد به مدرسان \\
\hline$-\cdot / 4 q V$ & $-\cdot /$ TAS & $0 \cdot-1$. & $1 . / 90$ & $r \varphi / M$ & احساس هويت نسبت به تحصيل \\
\hline$-1 / \cdot 1$ & $\cdot / \cdots$ & $r \cdot-\wedge$ & $r / M$ & $\mid F / F \Delta$ & عملكرد تحصيلى \\
\hline.$- / 9 \cdot 9$ & .1 .91 & $r \cdot-\wedge$ & $r / \cdot 1$ & $\mid f / \pi r$ & 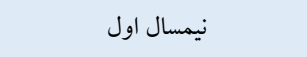 \\
\hline.$- / 9.4$ & $\cdot / \cdot r$ & $r \cdot-\wedge$ & r/QF & $14 / 99$ & 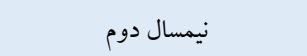 \\
\hline
\end{tabular}


نتايج ماتريس همبسـتِى ييرسـون نشــان داد بين معناى تحصـيلى با

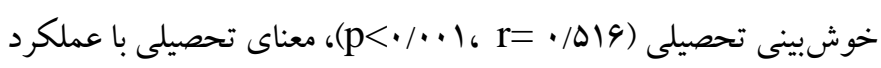

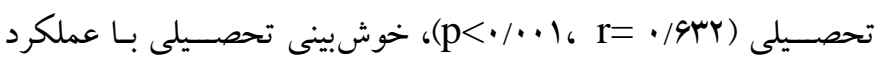

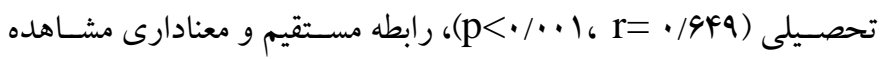
شــــ. جهـت بررســى فرضــــات يزوهش از روش الخويـابى معـادلات سـاختارى، بر اسـاس نرمافزار Mplus 7.4 اسـتفاده شـده است. به دليل عـدم برقرارى بيشفرض نرمـال جنــدمتغيرى از روش بر آورد كمترين

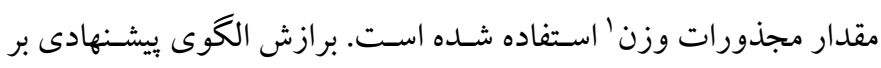
اسـاس شـاخص هاى برازند گیى مجذور خى ساتور ا-بنتلر با، نسبت مجذور خى به درجه آزادى، شـاخص برازش مقايسهاى ‘ شاخص ريشه ميانگين مجذور خطاى تقريب، شاخص ريشه استاندارد باقيمانده مجذور ميانگين و شـاخص توكر -لويس ه ارزيابى شـدند. توزيع تككمتغيره دادهها جهت بررسى توزيع طبيعى و دادههاى يرت به صسورت مجزا مورد بررسى قرار كرفت. وجود دادههاى يرت جندمتغيرى با اسـتفاده از روش مجذور دى دي

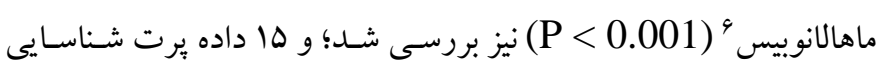
شده كه از تحليل خارج شدهاند.
I Vq/F. نتايج جدول ا نشـان داد ميانگين متغير هاى معناى تحصيلى

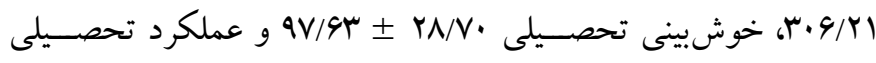

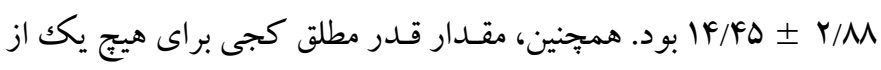

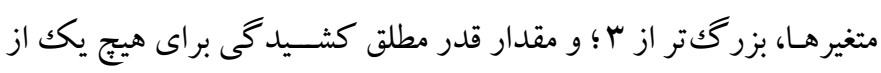
متغيرهـا، بزرككتر از · ا نبود. در نتيجـه مى توان بيـان كرد كـه انجـام اين تحليل از نظر نرمال بودن تككمتغيرى اشــكالى ندارد. جدول r اطللاعات مربوط به همبسـتكى بيرسـون بين معناى تحصيلى، خوشبينى تحصيلى و عملكرد تحصيلى آن را نشان مىدهد.

جدول ז: ماتريس همبستغى بين متغير هاى بيشبين، واسطهاى و وابسته مدل

\begin{tabular}{|c|c|c|c|}
\hline$r$ & $r$ & 1 & \\
\hline & & 1 & I. معناى تحصيلى \\
\hline & 1 & $\cdot / 019^{* * *}$ & r. خوشينى تحصيلى \\
\hline 1 & $.1949 \%$ & 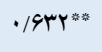 & r. عملكرد تحصيلى \\
\hline
\end{tabular}

$* * \mathrm{P}<\cdot / \cdot 1$, جدول r: شاخصهاى برازند مى الكوى بيشنهادى يزوهش حاضر

\begin{tabular}{|c|c|c|c|c|c|c|c|c|}
\hline SRMR & CFI & TLI & RMSEA & CMIN/DF & P-Value & df & $X^{2}$ & شاخصهاى برازندكى الكو \\
\hline $.1 .4 \Delta$ &.$/ 9 T V$ &.$/ 94$. & $\cdot / \cdot \mathrm{VA}$ & $r / A r$ & $<\cdot / \cdot \cdot 1$ & AV & YII/91 & الخوى ييشنهادى \\
\hline
\end{tabular}

و معناى تحصــلى مى توانند بو درصـــ از تغييرات عملكرد تحصـيلى را بيش بينى كنند كه اين ميز ان در حد قوى اسـت. همجِنين مشـاهده مىشود، ضريب تعيين متغير معناى تحصيلى ، ب درصد در حد متوسط است. جدول F نيز ضـرايب اسـتاندارد مسـيرها و شكل ا الكوى بيشنهادى مدل را نشان
نتايج جدول ب نشـان مى دهد الكوى بيشنهادى مدل بثزوهش از برازش

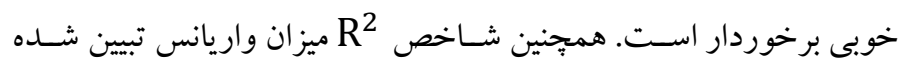

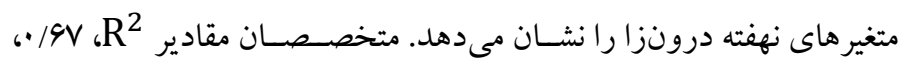
سا/ • و 19/ • رادر معادلات سـاختارى به ترتيب قوى، متوسـط و ضسعيف توصسيف مى كند. ضـريب تعيين متغير عملكرد تحصسيلى، AYF • است كه نشـان مىدهد تمامى متغيرهاى مسـتقل و ميانجى يعنى خوشبينى تحصيلى

جدول ع: ضرايب استاندارد مسيرهاى الكوى ييشنهادى

\begin{tabular}{|c|c|c|c|c|}
\hline سطح معنادارى(P) & نسبت بحرانى & خطاى معيار & ضر ايب استاندارد & 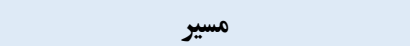 \\
\hline$<\cdot / \cdot \cdot 1$ & $\Lambda / \cdot v q$ & $\cdot / \cdot \Delta \Delta$ & $\cdot / F F A$ & خوشينى تحصيلى--->> عملكرد تحصيلى \\
\hline$<\cdot / \cdot \cdot 1$ & $1.19 \mathrm{VY}$ &.$/ .01$ & . /DFY & خوشينى تحصيلى_-->> معناى تحصيلى \\
\hline$<\bullet / \cdots 1$ & N/FTI &.$/ . \Delta F$ &.$/ 4 \Delta 1$ & معناى تحصيلى---> عملكرد تحصيلى \\
\hline
\end{tabular}

4. Root Mean Square Error of Approximation (RMSEA)

5. Tucker- Lewis Index (TLI)

6. Mahalanobis d-squared method
1. Weighted Least Squares (WLS)

2. Satorra-Bentler scaled chi-square (X2)

3. Comparative Fit Index (CFI) 


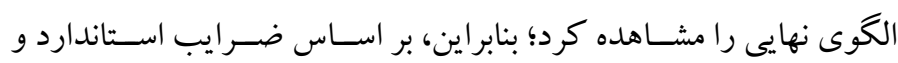
مقادير بحر انى ارائه شده در جدول سا، همه مسيرهاى مستقيم معنادار هستند

. $(\mathrm{P}<\bullet / .1)$

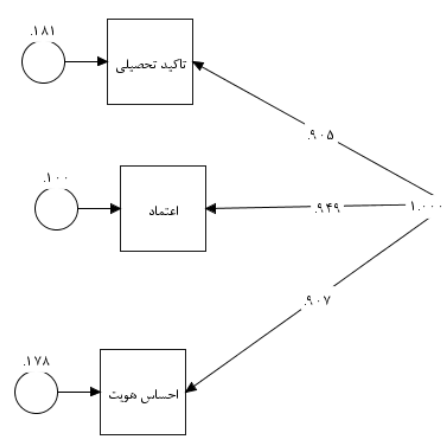

نتايج حاصـل از روابط مستقيم متغيرهاى يزوهش در مدل نهايى نشان مىدهـد كـه در كل نمونه تمامى ضـــرايب مسـير از لحاظ آمارى معنادار بودند. با اسـتناد به جدول م مى توان ضـر ايب اسـتاندارد كليه مسـيرها در

شكل ا: ضرايب استاندارد الكوى نهايى رابطه ساختارى خوشبينى تحصيلى با عملكرد تحصيلى از طريق واسطه كرى معناى تحصيلى در دانش آموزان دختر دبيرستانى شهر خرمدره

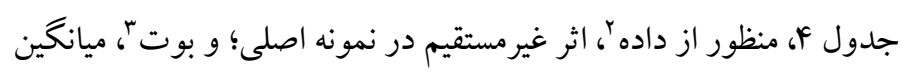

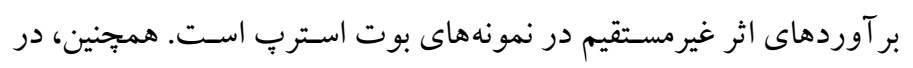

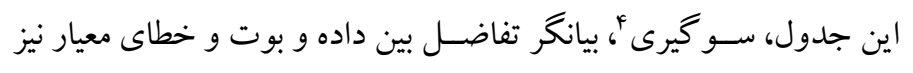

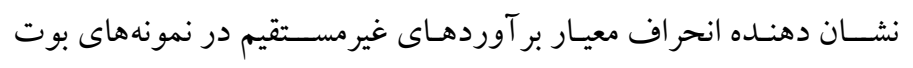
استرب است.
در الكوى نهايى يزوهش حاضـر يكك مسـير غيرمستقيم يا واسـطهاى

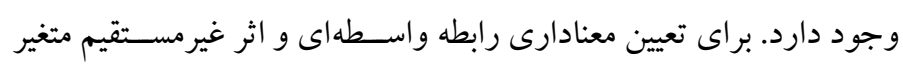

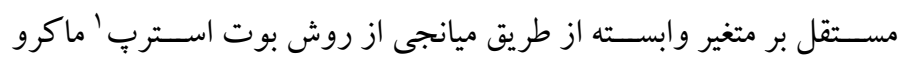

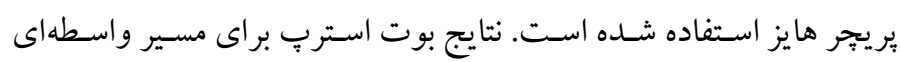

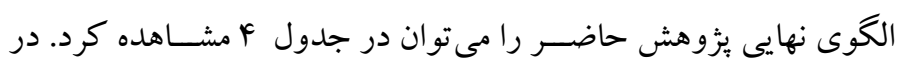

جدول ع: نتايج بوت استرب براى مسير غير مستقيم الكوى بروهش شاخص

\begin{tabular}{|c|c|c|c|c|c|c|c|}
\hline \multirow{2}{*}{ سطح معنادارى } & \multicolumn{6}{|c|}{ شاخص } & \multirow{2}{*}{ مسير } \\
\hline & حد بالا & حد يايين & خطا & سوكيرى & 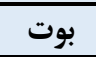 & داده & \\
\hline$<\cdot / \cdot \cdot 1$ &.$/ \cdot Y 99$ &.$/ \cdot I F r$ &.$/ \cdot r r$ & $\cdot / \cdots+1$ & $\cdot / \cdot r \cdot 1$ & $\cdot / \cdot Y \cdot$ & خوش بينى تحصيلى به عملكرد تحصيلى از طريق معناى تحصيلى \\
\hline
\end{tabular}

لحساظ آمـارى معنـادار اســـ؛ بنـابر اين معنـاى تحصـيلى در رابطـه بين

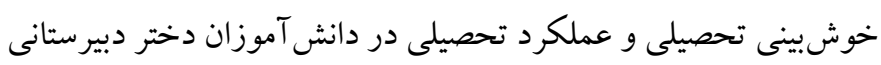
خرمدره نقش ميانجى گرى دارد.
نتـايج جـدول \& نشــان داد، حـد بِيايين فـاصــله اطمينان براى معناى تحصـيلى بـه عنوان متغير ميـانجى بين خوش بينى تحصـيلى و عملكرد

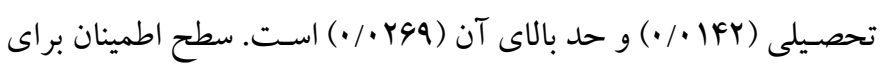

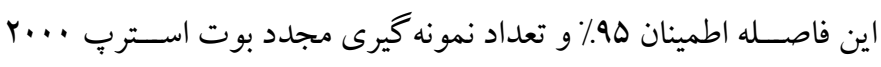

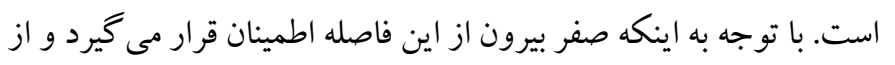

1. Bootstrap
2. Data
3. Boot

4. Bias 
بنابراين در كنار امور آموزشى بايد به عواطف و احساسات دانش آموزان نيز توجه ويزه شود.

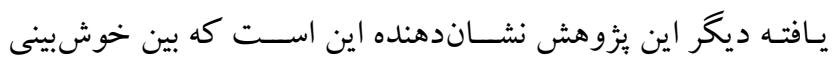

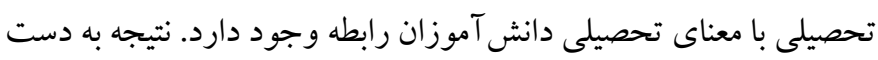

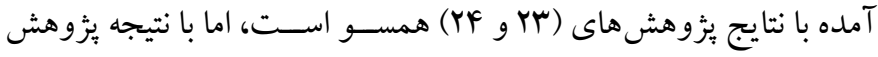

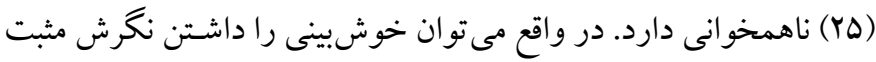
به جهان و يديدهها و ييامدها دانست؛ بنابر اين اين مسئله مى تواند در ايجاد

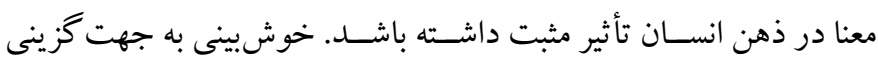

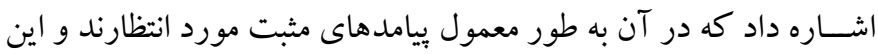

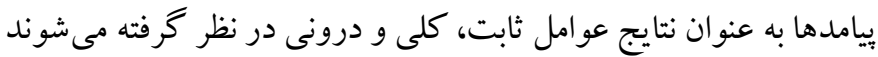

بس از جمع آورى دادههـا و اجر ایى مـدل، نتـايج بيـانغر اين بود كـه

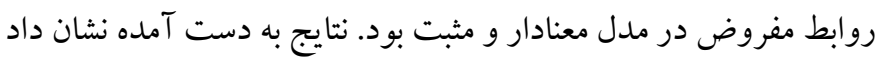

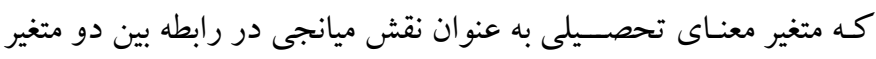

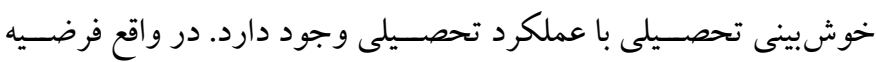

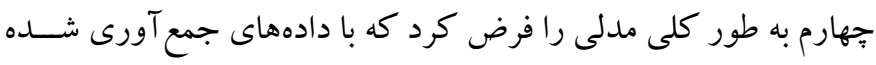

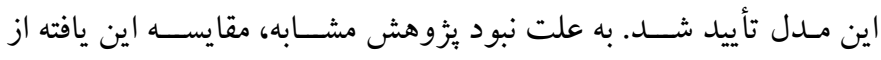

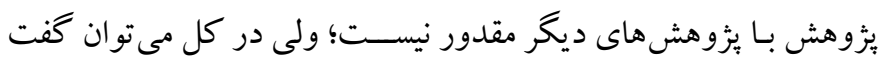

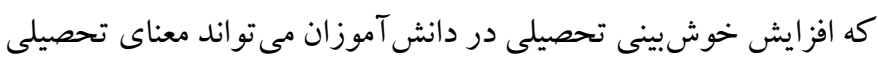
را در ابعـاد مختلف تقويست كنـــ و در نتيجـه اين متغيرهـا در كنـار هم

مى توانند موجب تقويت و بهبود عملكرد تحصيلى دانش آموزان شود.

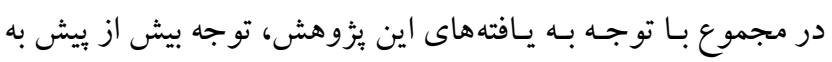

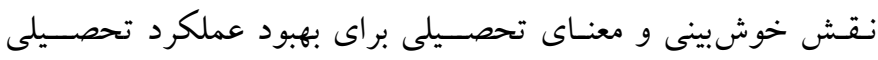

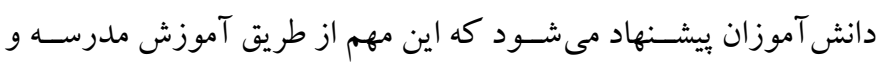

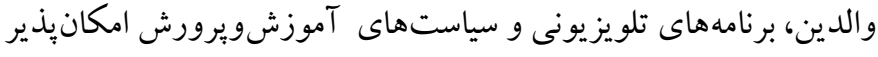

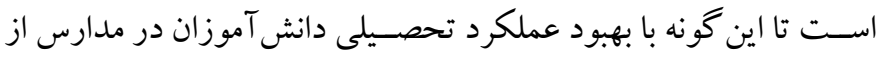

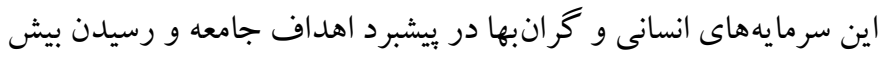
از ييش به جامعه آرمانى استفاده شود. از محدوديت هاى اصلى اين بزوهش مى توان به محدوديت جنسيت

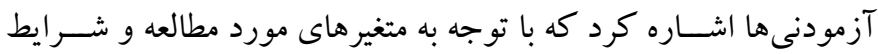

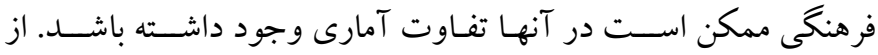

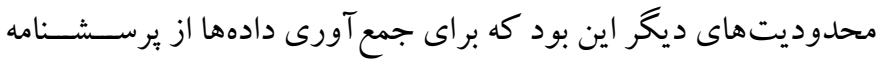

بحث و نتيجه كيرى

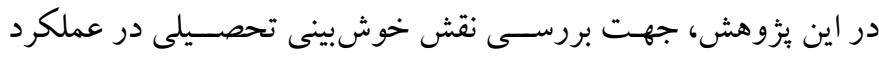

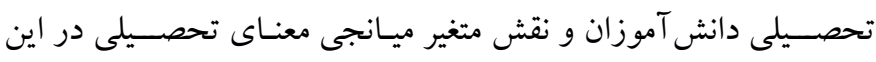

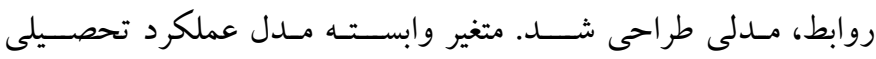

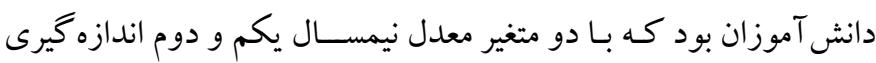

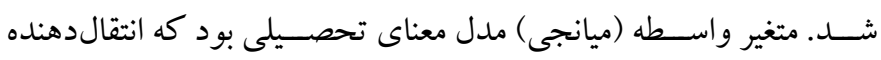

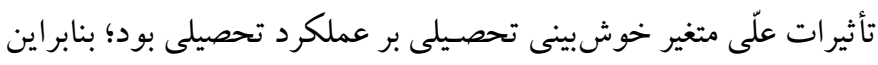

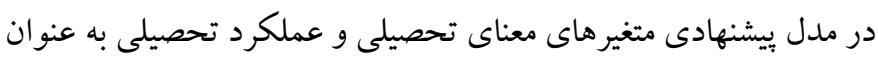

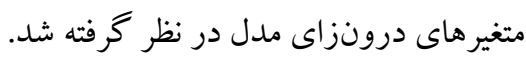

در اين مدل متغير خوشيينى تحصـيلى به عنوان متغير برونزاى مدل به صــورت مسـتقيم و غيرمسـتقيم بر عملكرد تحصـيلى دانش آموزان

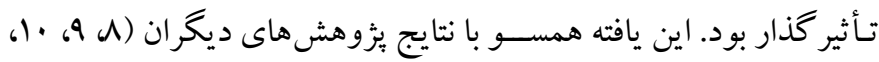

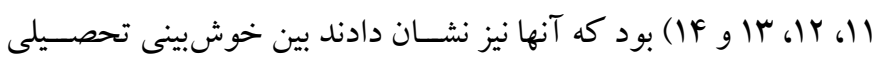
دانش آموزان و عملكرد تحصـيلى آنان رابطه وجود دارد. در تبيين اين

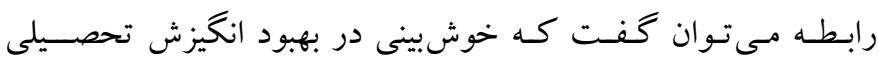

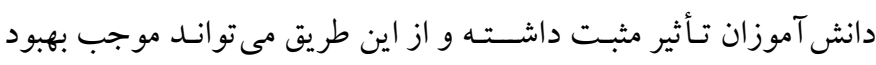

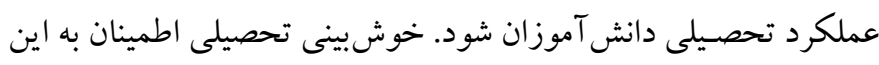

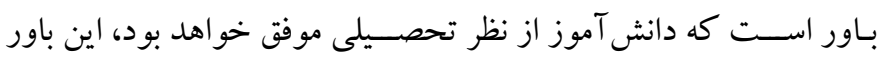

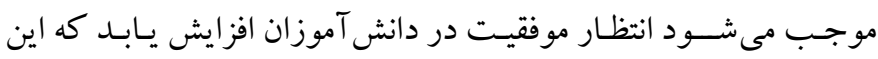

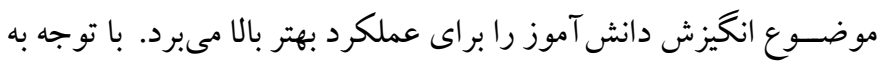

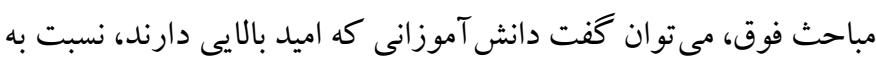

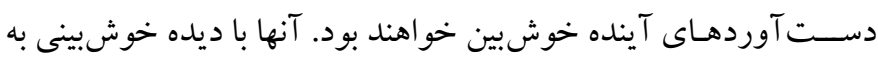

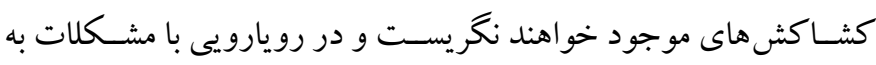

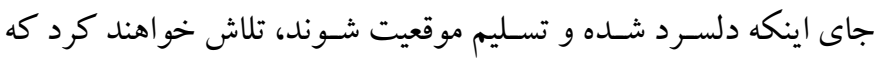
مسائل را به نحو مناسب حل و فصل كنند. نتـايج اين بزوهش همجنين نشــان داد كـه بين معنـاى تحصـيلى بـا

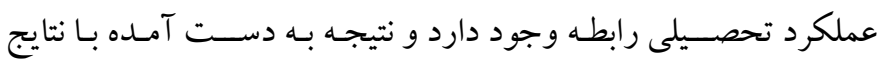

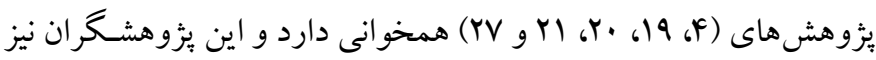

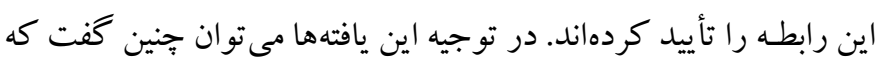
مسائل شناختى و عاطفى مربوط به موضوع تحصيل، بر بيشرفت و ارتقاى

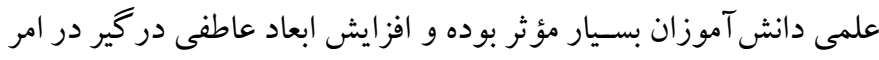

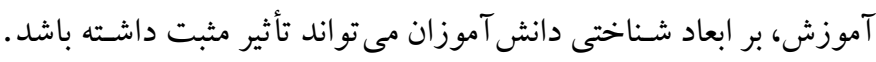




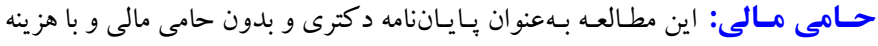
شخصى نويسند كان انجام شده است.

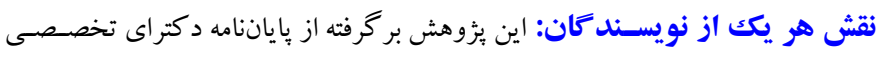

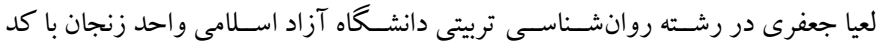

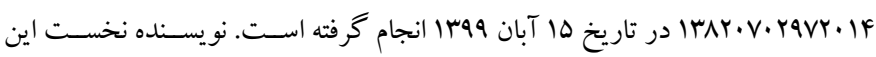

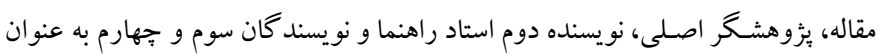
استادان مشاور بروزه نقش داشتهاند. تضـاد منافع: انجام اين ئزوهش براى نويسند كان هيج گُونه تعارض منافعى را به دنبال

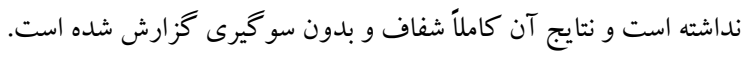

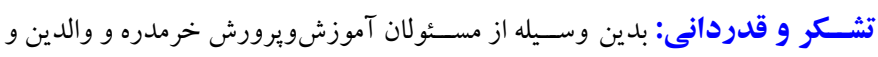
دانش آموزان شر كت كننده در اين يزوهش تشكر و قدردانى مىشود.
خود گزارشى اسـتفاده شـد كه ممكن اسـت برخى از افراد از ارائه باســخ

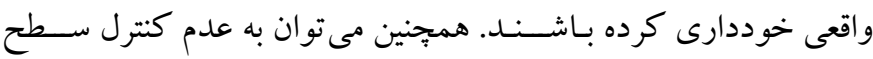
تحصـيلات والدين و وضعيت اقتصادى خانو اده اشاره كرد كه مى تو اند به عنوان عو امل تأثير گذار در شيوههاى تربيتى والدين باشد. بيشنهاد مى شود در يزؤهشهاى بعدى ســطح تحصــلات والدين و وضـعيت اقتصـادى خانواده مورد كنترل قرار كيرد.

ملاحظات اخلاقى

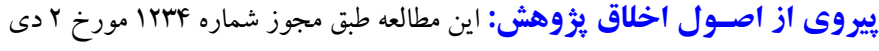
941ا توسط اداره آموزشويرورش خرمدره انجام شـده است. همجنين ملاحظات مانند

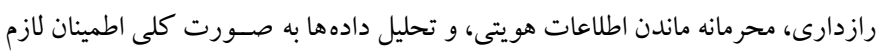
به افر اد شر كت كننده در يثوهش و والدين داده شد. 


\section{References}

1. Agasisti T, Avvisati F, Borgonovi F, Longobardi,S. Academic resilience: What schools and countries do to help disadvantaged students succeed in PISA. 2018. [Link]

2. Martin A, Marsh H. Academic resilience and its psychological and educational correlates: A construct validity approach. Psychol Sch. 2006; 43:267-81. [Link]

3. Owens RL, Allen BA, Maslowski AK, Murphy PK. Strengths Use, Environmental Factors, and Academic Outcomes in Newly Matriculated College Students. International Journal of Applied Positive Psychology. 2021, 1-23. [Link]

4. Jafari L, Hejazi M, Sibhi A. Investigating the relationship between academic resilience with students' academic performance and mediating academic meaning. Journal of School Psychology, 2020; 9 (3): 35-49. [Link]

5. Feldman DB, Kubot M. Hope, self-efficacy, optimism, and academic achievement: Distinguishing constructs and levels of specificity in predicting college gradepoint average. Learning and Individual Differences. 2015; 37: 210-216. [Link]

6. KulophasD, Ruengtrakul A, Wonggwanich S. The relationships among authentic leadership, teachers' work engagement, academic optimism and school size as moderator: A conceptual model. Procedia-Social and Behavioral Sciences. 2015; 191: 2554-2558. [Link]

7. Eren, A. Prospective teachers' future time perspective and professional plans about teaching: The mediating role of academic optimism. Teaching and Teacher Education, 2012; 28 (1)111-123. [Link]

8. Icekson T, Kaplan O, Slobodin O. Does optimism predict academic performance? Exploring the moderating roles of conscientiousness and gender. Stud High Educ [Internet]. 2020 Mar 3 [cited 2020 Oct 29]. 45(3):63547. [Link]

9. Hamedi Nasab S, Asgari A, Ayati M. The relation between academic optimism and motivation of academic advancement with respect of mediating role of academic efficacy of the second grade students. Int J Soc Sci Educ [Internet]. 2015; Oct 8.5:2223-4934. [Persian]. [Link]

10. Mehrian A, Janaabadi H, Pourghaz A. Relationship between academic meaning and perceived stress and academic optimism in Neishabour students. Journal of
Educational Psychology Studies. 1398; 16 (33): $137-$ 56. [Persian]. [Link]

11. ANDERSON, Karen, et al. Academic optimism, enabling structures, and student achievement: Delving into relationships. Journal of School Leadership, 2018; 28 (4)434-461. [Link]

12. SMITH PA, HOY WK. Academic optimism and student achievement in urban elementary schools. Journal of Educational Administration, 2007; 45(5): 556-568. [Link]

13. Cheraghikhah Z; Arabzadeh M, Kadivar P. The Role of Academic Optimism, Academic Emotions and School Well-Being in Mathematical Performance of Students. Positive Psychology. 2015; 1 (3):11-20. [Link]

14. Moradi K, Vawzi M, Farzaneh M, Mirzaei M. Relationship between academic optimism and academic achievement in boys high schools students of districts 6, 9 in Tehran city. Research in School and Virtual Learning. 2015; 5(2): 69-80. [Link]

15. Levine A, Cureton JS. When Hope and Fear Collide: A Portrait of Today's College Student. The JosseyBass Higher and Adult Education Series. [Internet]. San Francisco, California: Jossey-Bass; 1998 [cited 2020 Nov 23].

16. Henderson-King D, Mitchell AM. Do materialism, intrinsic aspirations, and meaning in life predict students' meanings of education?. Soc Psychol Educ 14, 119-134 (2011). [Link]

17. Alexander WS. An Empirical Typology of College Students. J Coll Stud Dev. 1993; 4(1):36-46. [Link]

18. Weiner E. The meaning of education for university students with a psychiatric disability: A grounded theory analysis. Psychiatr Rehabil J. 1999; 22(4): 403 409. [link]

19. Kadkhodai MA, Karami Z. Investigating the relationship between optimism and the meaning of education with students' academic motivation. Higher Education Research and Planning Institute. 1395; 9 (36): 143-59. [Persian]. [Link]

20. Senobar A, Raeisi E. The role of achievement goals and academic meaning in predicting academic success of girl students. Rooyesh. 2018; 7 (3):37-52. [Link]

21. Ortega-Maldonado A, Salanova M. Psychological capital and performance among undergraduate students: the role of meaning-focused coping and satisfaction. Teaching in Higher Education .2018; 23(3), 390-402. [Link]

22. Krypel MN, Henderson-King D. Stress, coping styles, and optimism: are they related to meaning of education in students' lives?. Soc Psychol Educ. 2010; 13, 409-424. [Link] 
23. Kadkhodaei, M. S., \& Karami, Z. The Relationship between Optimism and Meaning of Education with Academic Motivation of Students. Higher Education Letter, 2017, 9(36), 143-159. [Link]

24. Isa Zadegan A, Mikaeli FM, Marvi Milan F. The relationship between hope, optimism and the meaning of education with academic performance of preuniversity students. School Psychology Quarterly. 1393; 3 (2): 137-152 [Persian]. [Link]

25. Mehriyan E, Jenaabadi H, Pourghaz A. The relationship between meanings of education with perceived stress Academic Optimism. Journal of Educational Psychology Studies. 2019; 16(33), 137-156. [Link]

26. Sharifi PH. Sharifi N. Principles of Psychometrics and Psychoanalysis. Ninth Edition. Tehran: Roshd. 2019; pp: 252-376. [Persian]
27. Henderson-King D, Smith N M. Meanings of education for university students: Academic motivation and personal values as predictors. Social psychology of education. 2006; 9, 195- 221. [Link]

28. Megan T M, Regina BA, Mitchell, Roxanne MM. Moore, Dennis MM. Student academic optimism: A confirmatory factor analysis. Journal of Educational Administration. 2013; 51 (2), 150-175. [Link]

29. Moradi K, Vaezi M, Farzaneh M, and Mirzaei M. The Relationship between Academic Optimism and Academic Achievement among Boys' High School Students in Districts 6 and 9 of Tehran. Payam Noor University. 1393; 2 (5): 69-80. [Persian]. [Link] 